\title{
ARTICLE
}

Clinical Research

\section{What is the minimal dose for resistance exercise effectiveness in prostate cancer patients? Systematic review and meta-analysis on patient-reported outcomes}

\author{
Pedro Lopez $\mathbb{E}^{1,2} \cdot$ Dennis R. Taaffe $\mathbb{I}^{1,2} \cdot$ Robert U. Newton $\mathbb{1}^{1,2,3} \cdot$ Laurien M. Buffart ${ }^{1,4} \cdot$ Daniel A. Galvão $\mathbb{D}^{1,2}$
}

Received: 28 July 2020 / Revised: 22 October 2020 / Accepted: 4 November 2020 / Published online: 20 November 2020

(c) The Author(s) 2020. This article is published with open access

\begin{abstract}
Background Active treatments for prostate cancer are well known to result in several adverse effects such as fatigue, depression and anxiety symptoms, impacting the overall quality of life $(\mathrm{QoL})$ and wellbeing of a considerable proportion of patients. Resistance-based exercise interventions have shown positive effects to reduce or mitigate these treatment-related side effects. However, the minimal dosage required to derive these benefits is unknown. We systematically reviewed the resistance training effects in prostate cancer patients to determine the minimal dosage regarding the exercise components (mode, duration, volume and intensity) on fatigue, QoL, depression and anxiety.

Methods Using PRISMA guidelines, MEDLINE, CINAHL, EMBASE, SPORTDiscus and Web of Science databases were searched. Eligible randomised controlled trials examined prostate cancer patients undertaking resistance-based exercise programs during or following treatment. Meta-analysis was undertaken when more than three studies were included. Associations between resistance exercise components and its effects were tested by meta-regression analysis.

Results Eighteen trials involving 1112 men with prostate cancer were included. Resistance-based exercise programs resulted in significant effects on fatigue (effect size $=-0.3,95 \% \mathrm{CI}:-0.4$ to $-0.2, P<0.001$ ) and QoL (effect size $=0.2,95 \% \mathrm{CI}$ : 0.0 to $0.4, P=0.018$ ), with significant effects in specific questionnaires and domains of these outcomes. Resistance-based exercise effects on depression (effect size $=-0.3,95 \% \mathrm{CI}:-0.7$ to 0.0 ) and anxiety symptoms (effect size $=-0.3,95 \% \mathrm{CI}$ : -0.5 to 0.0$)$ were positive but not significant $(P=0.071$ to 0.077$)$. Meta-regression indicated no significant association between resistance exercise components with fatigue and QoL outcomes $(P=0.186-0.689)$.

Conclusions Low volume resistance exercise undertaken at a moderate-to-high intensity is sufficient to achieve significant fatigue and QoL benefits for men with prostate cancer and also mitigate depression and anxiety symptoms. A lower resistance exercise dosage than usually prescribed may help enhance adherence by reducing exercise barriers.
\end{abstract}

Supplementary information The online version of this article (https:// doi.org/10.1038/s41391-020-00301-4) contains supplementary material, which is available to authorized users.

Pedro Lopez

plopezda@our.ecu.edu.au

1 Exercise Medicine Research Institute, Edith Cowan University, Perth, WA, Australia

2 School of Medical and Health Sciences, Edith Cowan University, Perth, WA, Australia

3 School of Human Movement and Nutrition Sciences, University of Queensland, Brisbane, QLD, Australia

4 Department of Physiology, Radboud University Medical Center, Radboud Institute for Health Sciences, Nijmegen, the Netherlands

\section{Introduction}

Several treatments are used to delay cancer progression and enhance survival such as androgen deprivation therapy (ADT) and radiotherapy in men with prostate cancer [1]. However, most patients are likely to face an array of treatment-related adverse effects during and after the course of treatment [2]. Among them, fatigue, depression and anxiety symptoms affect $\sim 20$ to $40 \%$ of men with prostate cancer undergoing primary treatment (e.g. surgery, radiotherapy and ADT), impacting their overall quality of life and wellbeing during and even following treatment [3-5].

Over the past decade, a substantial number of exercise trials have reported significant benefits to quality of life and fatigue in prostate cancer patients during ADT or following treatment when undertaking resistance-based exercise [6-9] 
with some of them also presenting modest changes in depression and anxiety symptoms $[10,11]$. In the most recent exercise guideline for cancer patients [12], a resistance exercise prescription of two sets of 8-15 repetitions at $60-85 \%$ of one-repetition maximum (1-RM) in combination with aerobic exercise was recommended to counter anxiety, fatigue and depressive symptoms. However, most work underlying this recommendation was derived from trials in breast cancer patients and survivors, and there is a paucity of comparative trials regarding the resistance training components. As a result, it is unclear if this would be the most appropriate recommendation, especially in prostate cancer patients. This may be especially the case as to date there has only been a single trial comparing different resistance training frequencies in this patient group [13]. The study of Norris et al. [13] compared resistance training undertaken twice or three times per week for 12 weeks in prostate cancer survivors and did not observe any differences in quality of life, fatigue, depression or anxiety symptoms. The authors suggested that twice weekly training may be sufficient to provide benefits in these outcomes given the time constraints and possible exacerbation of symptoms such as fatigue related to undertaking exercise 3 days per week [13]. Although a promising result, it remains unknown if a resistance training volume and intensity, even lower than that previously suggested [12], may represent a minimal and sufficient stimulus for improvements in patient-reported outcomes in prostate cancer patients at different treatment stages. This is important given the role of resistance exercise to counter treatment-related toxicities in men with prostate cancer $[2,12]$. Furthermore, despite several systematic reviews examining exercise effects in prostate cancer patients [14-19], none have addressed the minimal exercise dosage required for improvements in common patient-reported outcomes.

As a result, the aim of this review was to: (1) systematically review and analyse the resistance-based training effects on fatigue, quality of life, depression and anxiety outcomes in men with prostate cancer given their importance for patient wellbeing; and (2) examine the doseresponse relationship between the prescribed exercise components (i.e. mode, duration, volume and intensity) and responses on those outcomes.

\section{Methods}

\section{Study selection procedure}

The systematic review was undertaken in accordance with the Preferred Reporting Items for Systematic Reviews and Meta-Analyses (PRISMA) statement [20, 21].
Furthermore, the method used was based on the minimum criteria established by the Cochrane Back Review Group (CBRG) [22].

This review included published data from randomised controlled trials evaluating the effects of supervised resistance-based exercise programs in prostate cancer patients at any treatment stage (including post treatment). The primary outcome for this review was fatigue, with secondary outcomes of quality of life, depression and anxiety. The exclusion criteria were: (1) home-based exercise as the only intervention during the intervention period due to lack of direct supervision and inability to quantify training variables (e.g. kilograms used as a resistance with resistance training machines or dumbbells in clinic-based programs compared to elastic bands or bodyweight often used in home-based programs); (2) trials involving mixed cancer patients without specific information on the results for prostate cancer patients; (3) trials not including or reporting on the specific outcomes for this review, or did not include sufficient information for analysis (e.g., baseline and post-intervention assessment, or within- and betweengroups mean difference); and (4) written in a language other than English. In the search strategy, titles and abstracts were first independently evaluated. When abstracts did not provide sufficient information, they were selected for full-text evaluation. Eligibility was assessed independently by two reviewers, with differences resolved by consensus.

We included publications up to November 2019 using the following electronic databases: MEDLINE, CINAHL, EMBASE, SPORTDiscus and Web of Science. The terms used were: 'prostate cancer' and 'resistance training' in association with a list of sensitive terms (Supplementary Material Table S1). In addition, we also performed a manual search of the reference lists provided in the selected papers as well as previous systematic reviews and meta-analytic studies in patients with prostate cancer [14-19] to detect studies potentially eligible for inclusion.

\section{Data extraction}

The data extraction was performed via a standardised form. Clinical information of the patients such as age, disease stage and treatment phase and intervention characteristics that included duration, components of resistance training such as prescribed modality, frequency, intensity and volume, adherence (i.e. number of patients that completed the program), attendance (i.e. number of sessions attended), compliance (i.e. number of patients that successfully completed the exercise prescription) and adverse events were extracted along with the main outcomes. Information was always extracted for the longest period of the supervised exercise intervention, while outcomes were extracted in their absolute units (e.g., questionnaire scores). 


\section{Assessment of risk of bias}

The risk of bias was evaluated according to the 2 nd version of the Cochrane risk-of-bias tool for randomised trials (RoB 2) [23] with each assessment focused at the outcome level. The six-domain instrument includes: (1) randomisation process; (2) deviation from intended interventions; (3) missing outcome data; (4) measurement of the outcome; (5) selection of the reported result and (6) overall bias. Overall risk of bias was expressed as "low risk of bias" if all domains were classified as low risk, "some concerns" if some concern was raised in at least one domain but not classified as at high risk in any other, or "high risk of bias" if at least one domain was classified as high risk, or have multiple domains with some concerns [23].

\section{Data analysis}

For the meta-analysis, the pooled effect estimates were obtained from the standardised mean difference (SMD) combining different questionnaire scores for the same respective outcome, and mean difference (MD) for each individual questionnaire, of baseline to the final assessment corresponding to the period of the intervention. Analyses were conducted for all studies and a subgroup analysis was provided for low risk randomised controlled trials based on RoB 2.0 when more than three studies were available. Fatigue was assessed using the following instruments: the Functional Assessment of Cancer Therapy-Fatigue (FACT-F) [24], European Organisation for Research and Treatment of Cancer Quality of Life Questionnaire C30Fatigue (EORTC QLQ-C30 Fatigue $_{\text {) }}$ [25], Multidimensional Fatigue Symptom Inventory-Short Form (MFSI-SF) [26], Functional Assessment of Chronic Illness Therapy (FACIT) [27], Brief Fatigue Inventory (BFI) [28], and the Schwartz Cancer Fatigue Scale [29] questionnaires. The Functional Assessment of Cancer Therapy-Prostate (FACT-P) andGeneral (FACT-G) [30], the 36-Item Short-Form Health Survey (SF-36) physical and mental health composite [31] and EORTC QLQ-C30-Global [32] were used to assess quality of life. The Center for Epidemiologic Studies (CESD) [33] and Brief Symptom Inventory-18-Depression (BSI-18 Depression $_{\text {) were }}$ used to assess depression, and the BSI-18 Anxiety [34] and Memorial Anxiety Scale for Prostate Cancer (MAX-PC) [35] to assess anxiety. The questionnaires with their respective characteristics (number of items, scaling and scores), minimally important difference (MID) and cut-off points are described in Table 1. In questionnaires reverse scaled for fatigue, depression and anxiety outcomes, where higher values indicate better outcomes rather than poorer outcomes, the mean in each group was multiplied by -1 as recommended in the Cochrane Handbook [36].
In studies with multiple exercise interventions vs. a single control group, data from exercise groups was combined according to the Cochrane Handbook [36]. Calculations were performed using a random-effects model with the DerSimonian \& Laird method [37]. Statistical significance was assumed when the mean difference effect reached an $\alpha$ value $\leq 0.05$. Effect size (ES) were according to Cohen [38] with values of 0.0 to $<0.5$ indicating small, values of 0.51 to $<0.8$ indicating medium, and values $\geq 0.8$ indicating large effects. Statistical heterogeneity was assessed using the Cochran Q test [39]. A threshold $P$ value of 0.1 , as well as values greater than $50 \%$ in $\mathrm{I}^{2}$ were considered indicative of high heterogeneity [39]. We examined heterogeneity using sensitivity analysis by omitting one study at a time. Publication bias was explored by contour-enhanced funnel plots and Egger's test [40], and, if necessary, trim-and-fill computation was used to estimate the effect of publication bias on the interpretation of results $[39,41]$. Analyses were conducted using the package metan, confunnel, metabias, and metatrim from Stata 14.0 software (Stata, Texas, USA). Forest plots presented for the outcome measures are after sensitivity analysis and/or trim-and-fill procedure adjustments.

In addition, we tested the association between exercise components (mode, intervention duration, prescribed weekly volume and peak intensity) and SMD effects to identify a dose-response relationship. Using one or multiple variables at a time we assessed whether exercise components influence the association of resistance-based exercise with the main effects. Analyses were undertaken in outcomes significantly affected by exercise provided the models had more than 5 studies. For intervention duration, prescribed weekly volume and peak intensity, analyses were considered when the range was higher than $5 \%$, while exercise mode was coded as $0=$ resistance training alone and $1=$ resistance training combined with other components (e.g. aerobic, flexibility, impact-loadingor balance). Correlations were weighted by the inverse of the variance of each observation and the coefficient of determination $\left(r^{2}\right)$, the statistical test of heterogeneity $\left(\mathrm{I}^{2}\right)$, component coefficients, standard errors (SE) and 95\% CI are presented for each outcome with their respective $P$ values. Analyses were conducted using the package metareg from Stata 14.0 software (Stata, College Station, USA).

\section{Results}

\section{Studies included}

Of the 1030 retrieved studies, 794 were retained for screening after duplicate removals. Of these, 694 were excluded and 100 full-text articles were assessed for eligibility (Fig. 1) in accordance with the inclusion criteria. The eligibility 
Table 1 Patient reported outcome questionnaires for fatigue, quality of life, depression and anxiety.

\begin{tabular}{|c|c|c|c|c|}
\hline Questionnaire & Items and scaling & Score & MID & $\begin{array}{l}\text { Cut- } \\
\text { off point }\end{array}$ \\
\hline \multicolumn{5}{|l|}{ Fatigue } \\
\hline FACT-F [24] & $\begin{array}{l}13 \text { items; 5-point Likert } \\
\text { rating scale }\end{array}$ & $\begin{array}{l}52 \\
\text { High_Less fatigue }\end{array}$ & 3 pts [67] & 34 pts [68] \\
\hline FACIT-Fatigue [27] & $\begin{array}{l}13 \text { items; 4-point Likert } \\
\text { rating scale }\end{array}$ & $\begin{array}{l}52 \\
\text { High—Less fatigue }\end{array}$ & NR & 43 pts [69] \\
\hline MFSI-SF [26] & $\begin{array}{l}30 \text { items; 4-point Likert } \\
\text { rating scale }\end{array}$ & $\begin{array}{l}72 \\
\text { High-More fatigue }\end{array}$ & NR & NR \\
\hline BFI [28] & $\begin{array}{l}9 \text { items; } 11 \text {-point Likert } \\
\text { rating scale }\end{array}$ & $\begin{array}{l}10 \\
\text { High-More fatigue }\end{array}$ & NR & NR \\
\hline $\begin{array}{l}\text { Schwartz Cancer } \\
\text { Fatigue Scale [29] }\end{array}$ & $\begin{array}{l}28 \text { items; 5-point Likert } \\
\text { rating scale }\end{array}$ & $\begin{array}{l}36 \\
\text { High-More fatigue }\end{array}$ & 5 pts [70] & NR \\
\hline $\begin{array}{l}\text { EORTC QLQ- } \\
\text { C30 Fatigue } \\
\text { [25] }\end{array}$ & $\begin{array}{l}3 \text { items; 4-point Likert } \\
\text { rating scale }\end{array}$ & $\begin{array}{l}100 \\
\text { High-More fatigue }\end{array}$ & 5 pts [71] & NR \\
\hline \multicolumn{5}{|l|}{ Quality of life } \\
\hline FACT-G [30] & $\begin{array}{l}27 \text { items; 5-point Likert } \\
\text { rating scale }\end{array}$ & $\begin{array}{l}100 \\
\text { High-Better QoL }\end{array}$ & 4 pts [67] & $\begin{array}{l}61.3 \mathrm{pts} \\
{[72]}\end{array}$ \\
\hline FACT-P [30] & $\begin{array}{l}12 \text { items; 5-point Likert } \\
\text { rating scale }\end{array}$ & $\begin{array}{l}48 \text { or } 148^{\mathrm{a}} \\
\text { High-Better QoL }\end{array}$ & NR & $\begin{array}{l}76.0 \mathrm{pts} \\
{[73]}\end{array}$ \\
\hline $\begin{array}{l}\text { EORTC QLQ-C30 } \\
{[32]}\end{array}$ & $\begin{array}{l}\text { 4- and 7-point Likert } \\
\text { rating scale }\end{array}$ & $\begin{array}{l}100 \\
\text { High-Better QoL }\end{array}$ & $\begin{array}{l}5-10 \text { pts-small } \\
\text { change; } \\
10-20 \text { pts- } \\
\text { moderate change; } \\
>20 \text { pts-large } \\
\text { change }[74,75]\end{array}$ & $\begin{array}{l}70.0 \mathrm{pts} \\
{[76]}\end{array}$ \\
\hline SF-36 [31] & $\begin{array}{l}36 \text { items; } 3-, 5-\text { and 6- } \\
\text { point Likert rating scale }\end{array}$ & $\begin{array}{l}100 \\
\text { High_Better QoL }\end{array}$ & 5 pts [77] & NR \\
\hline \multicolumn{5}{|l|}{ Depression } \\
\hline CES-D [33] & $\begin{array}{l}20 \text { items; 4-point Likert } \\
\text { rating scale }\end{array}$ & $\begin{array}{l}60 \\
\text { High-Greater } \\
\text { depressive } \\
\text { symptoms }\end{array}$ & NR & NR \\
\hline BSI-18 Depression [34] & $\begin{array}{l}18 \text { items; } 5 \text {-point Likert } \\
\text { rating scale }\end{array}$ & $\begin{array}{l}24 \\
\text { High-Greater } \\
\text { depressive } \\
\text { symptoms }\end{array}$ & NR & NR \\
\hline \multicolumn{5}{|l|}{ Anxiety } \\
\hline BSI-18 $8_{\text {Anxiety }}[34]$ & $\begin{array}{l}18 \text { items; } 5 \text {-point Likert } \\
\text { rating scale }\end{array}$ & $\begin{array}{l}24 \text { or T-scores } \\
\text { High-Greater } \\
\text { depressive } \\
\text { symptoms }\end{array}$ & NR & NR \\
\hline MAX-PC [35] & $\begin{array}{l}24 \text { items; 4-point Likert } \\
\text { rating scale }\end{array}$ & $\begin{array}{l}72 \\
\text { High-Greater } \\
\text { anxiety symptoms }\end{array}$ & NR & NR \\
\hline
\end{tabular}

BFI Brief Fatigue Inventory, BSI-18 Brief Symptom Inventory-18, CES-D Center for Epidemiologic Studies-Depression Scale, EORTC QLQC30 European Organisation for Research and Treatment of Cancer Quality of Life Questionnaire C30, FACIT Functional Assessment of Chronic Illness Therapy, FACT-F Functional Assessment of Cancer Therapy-Fatigue, FACT-G Functional Assessment of Cancer Therapy-Genera, FACT-P Functional Assessment of Cancer Therapy_Prostate, MAX-PC Memorial Anxiety Scale for Prostate Cance, MID minimally important difference, MFSI-SF Multidimensional Fatigue Symptom Inventory-Short Form, NR not reported elsewhere, SF-36 36-Item Short-Form Health Survey.

${ }^{\text {a }}$ Score based in the sum of FACT-G general score and the prostate cancer subscale.

assessment resulted in 18 [refs. 6-8, 10, 11, 42-54] studies that investigated the effect of resistance-based training (i.e. resistance training alone, combined with aerobic exercise or included in a multimodal exercise program) on patientreported outcomes in prostate cancer patients at any treatment stage. Sixteen studies were included in the dose-response 
Fig. 1 Flow chart of study selection process. Asterisk indicates primary outcome.

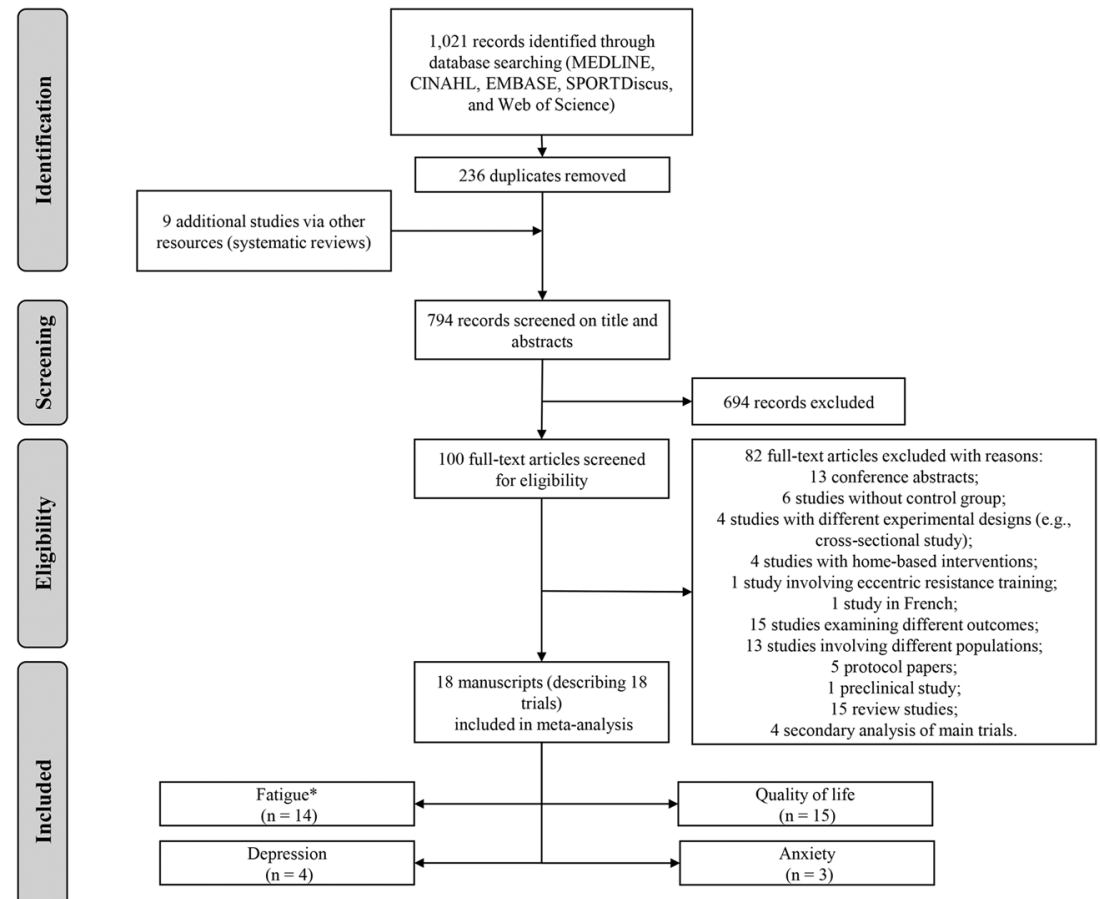

relationship analysis involving exercise mode, intervention duration, prescribed weekly volume and peak intensity and the effects on patient-reported outcomes.

\section{Prostate cancer patients and exercise intervention characteristics}

A total of 1112 prostate cancer patients with an average age of $69.6 \pm 2.2$ yrs participated in the included studies. Exercise interventions were predominantly undertaken in patients on ADT (14 of 18 studies) [6, 8, 10, 11, 42-44, $46-48,50,52-54]$. Exercise modalities included predominantly combined resistance and aerobic training ( 8 of 18 studies) [6-8, 10, 44, 46, 50, 54], followed by multimodal exercise programs (6 of 18 studies) $[8,11,47,49,51,53]$, and resistance training only (5 of 18 studies) $[42,43,45,48,52]$ in a cohort of 555 patients allocated to exercise intervention compared to 557 patients in the control group. A total of 13 studies [6, 10, 11, 42-46, 48-51, 54] compared an exercise intervention vs. usual care control, 4 [refs. 7, 47, 52, 53] were compared to a home-based intervention involving aerobic or flexibility training or to physical activity advice, and 1 [ref. 8] was compared to a delayed exercise group. Studies characteristics are shown in Table 2.

The mean exercise intervention duration was $17.3 \pm$ 9.5 weeks with either 2 [refs. $6-8,10,11,44-47,49,54]$ or 3. sessions per week $[42,43,48,50-53]$ (average: $2.5 \pm 0.8$ sessions per week). The average total prescribed resistance training volume was $8334 \pm 4568$ repetitions with a weekly training volume of $489 \pm 195$ repetitions which is equivalent to a training volume of $197 \pm 58$ repetitions per session ( 2 sets of 10 repetitions for 10 exercises). In addition, the highest peak intensity reached throughout the resistance training programs was $85 \%[6-8,11,48]$, followed by $83 \%$ [52], $80 \%$ [45, 47, 49], 75\% [50, 51], 70\% [42, 43] and $60 \%$ [46] of 1-RM. Information about resistance training volume was not reported by two studies [44, 53], while four studies [11, 44, 53, 54] did not report intensity. Exercise program adherence ranged from 70 to $94 \%$ (reported in 6 of 18 studies) [11, 42, 45-47, 52], while the attendance and compliance ranged from 65 to $94 \%$ (reported in 16 of 18 studies) [6-8, 10, 11, 42-45, 47, 49-54] and from 70 to $94 \%$ (reported in 5 of 18 studies) [44, 45, 49, 50, 53], respectively. Supervised exercise sessions were conducted in small groups of participants in seven studies $[6-8,10,45,50,51]$, while one study reported that exercise sessions were conducted with one participant at a time [53]. Adverse events related to the exercise interventions were identified in seven studies [7, 8, 11, 43, 49, 51, 54], while nine studies [6, 44-47, 49, 51, 52, 54] reported no adverse events during the intervention period, and 2 [refs. 11, 42] did not report this information.

\section{Risk of bias assessment}

For the primary outcome of fatigue, $7.1 \%$ of the studies presented some concern in risk of bias assessment (1 of 


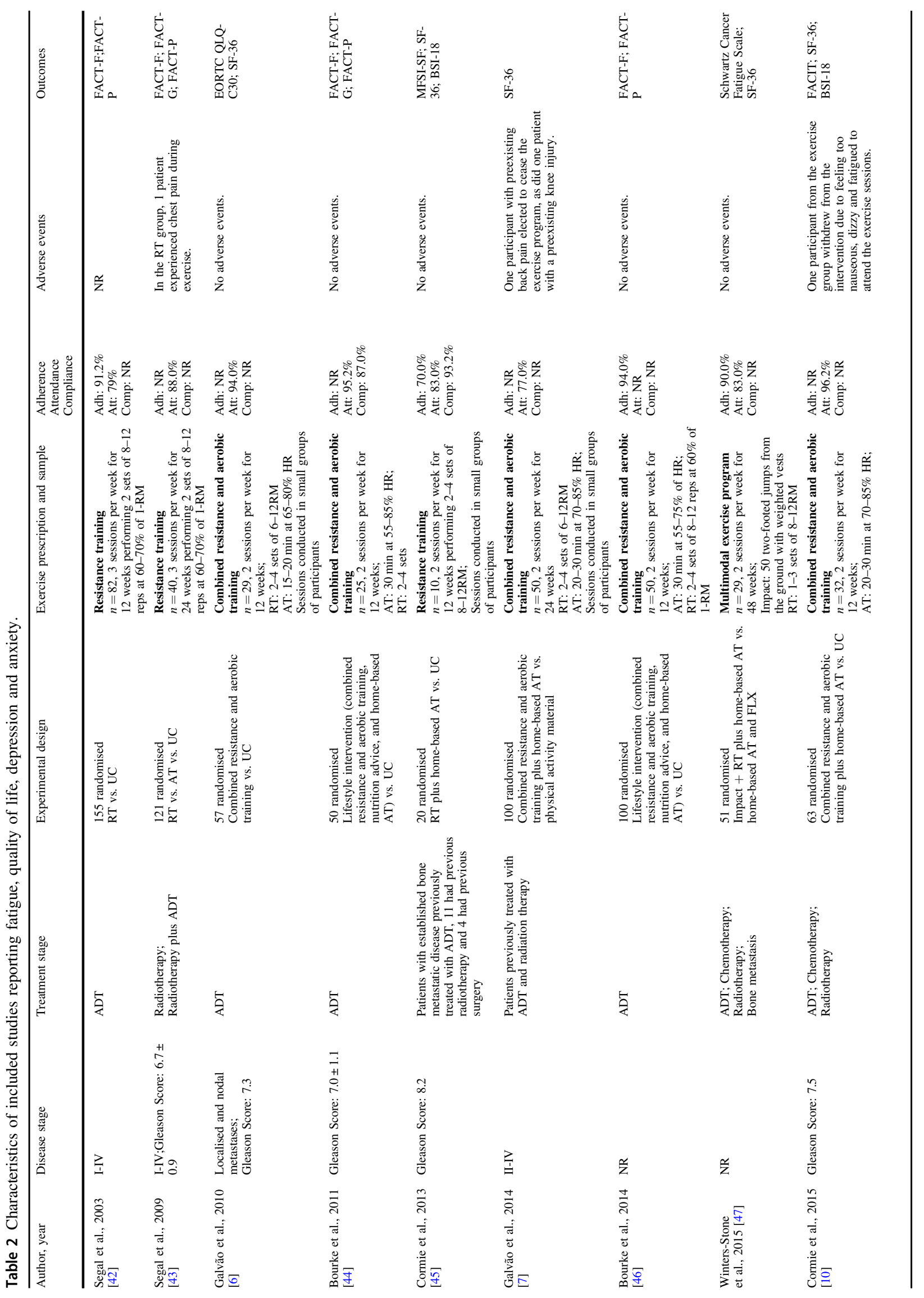




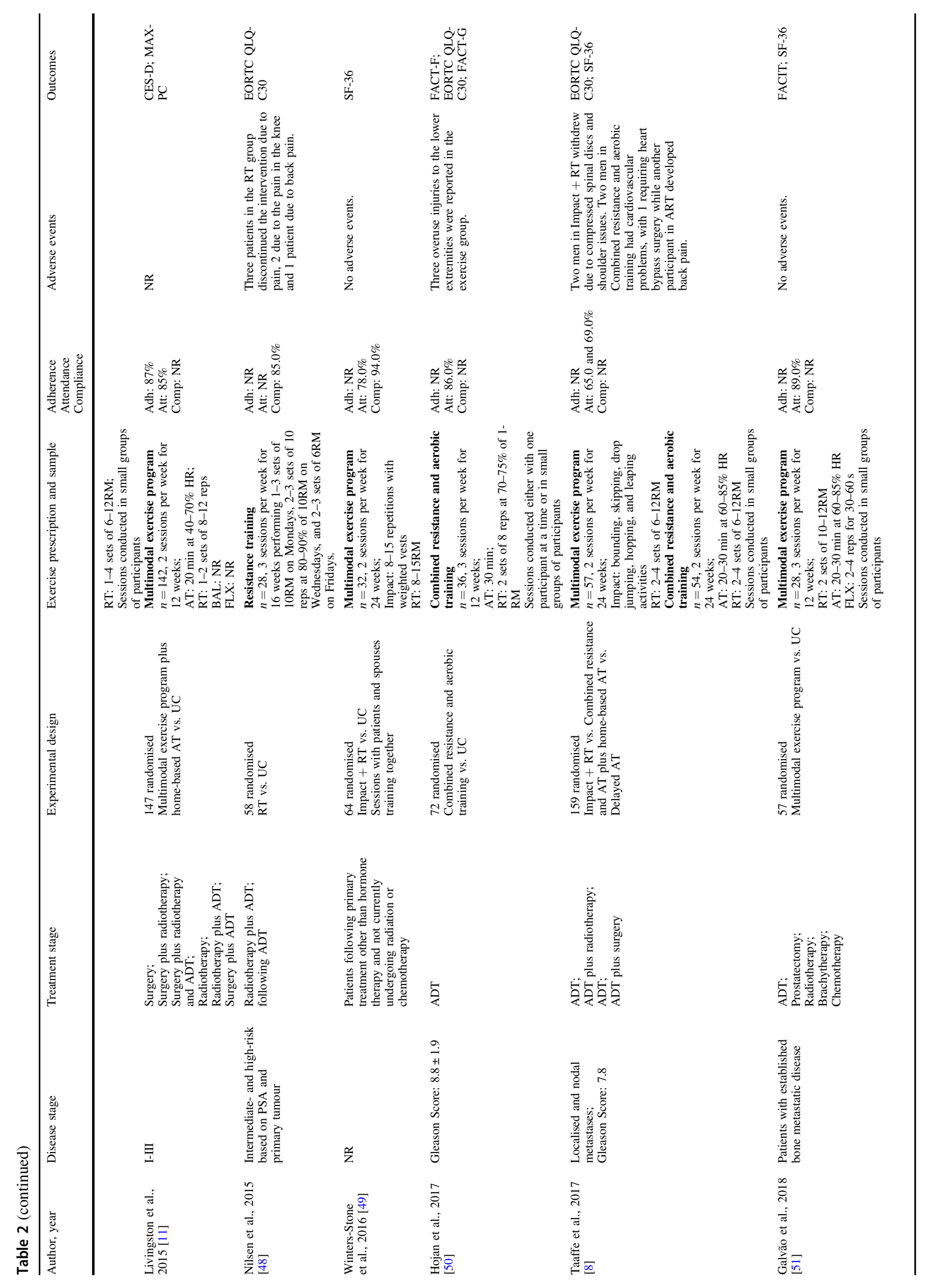




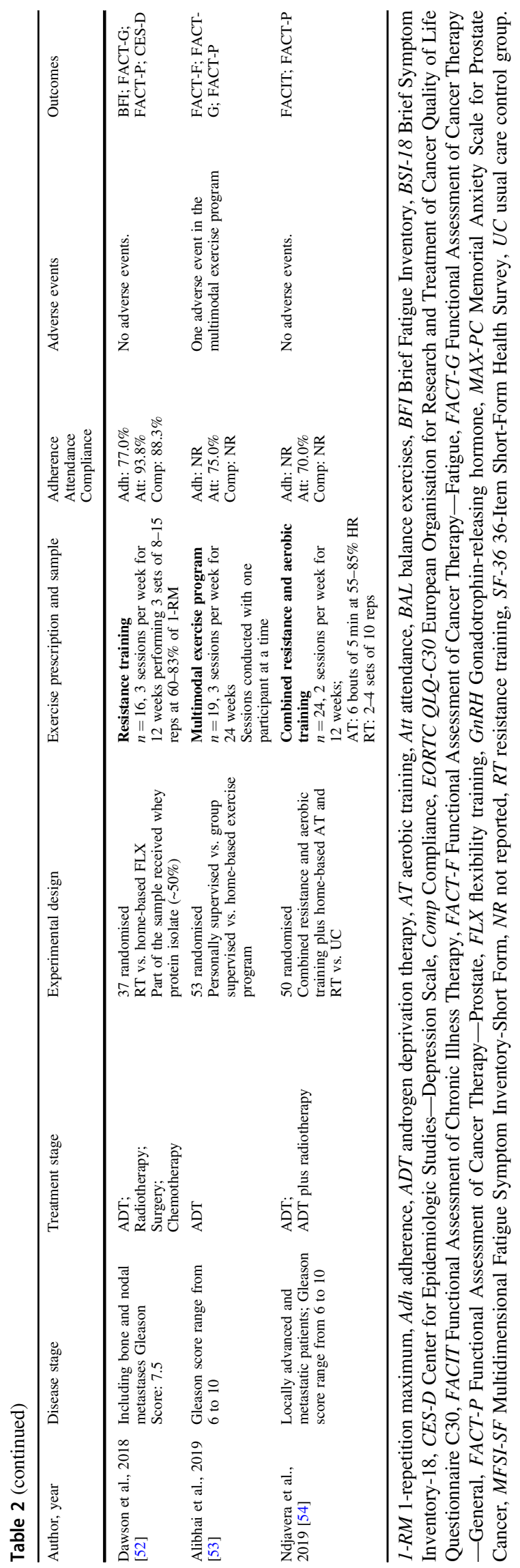

14 studies) [53]. The concern with the fatigue assessment was due to the selection of the reported result as one study did not report sufficient information for the outcome at baseline (1 of 14, 7.1\%; some concern) [53]. For the secondary outcomes, there was some concern of bias observed in quality of life $(13.3 \%, 2$ of 15 studies) [11, 53], depression (25.0\%, 1 of 4 studies) [11] and for the anxiety assessment (33.3\%, 1 of 3 studies) [11]. The risk of bias assessment for each outcome is shown in Table 3, while the individual assessment is shown in Supplementary Material Fig. S1.

\section{Exercise effects on fatigue}

For fatigue, exercise resulted in a significant overall mean ES of -0.3 (95\% CI: -0.4 to $-0.2, P<0.001)$ with $\mathrm{I}^{2}=$ $0 \%$ in 507 prostate cancer patients who undertook exercise interventions compared to 459 patients in control groups (Fig. 2). The result was maintained in the subgroup analysis involving the low risk studies. For questionnaires used to assess patient-reported fatigue, positive effects of -5.2 pts (95\% CI: -10.1 to -0.2 pts, $P=0.040)$ were found in the EORTC QLQ-C 30 Fatigue with $\mathrm{I}^{2}=31 \%$, and 3.9 pts (95\% CI: 2.6 to 5.3 pts, $P<0.001)$ with $\mathrm{I}^{2}=0 \%$ in the FACT-F. When low risk subgroup analyses were undertaken, all effects were maintained. There were insufficient data for the MFSI-SF, FACIT, BFI and Schwartz Cancer Fatigue Scale for further analysis. Hojan et al. [50] was considered an outlier in the overall and subgroup analysis for fatigue and for FACT-F being omitted from the abovementioned results. No publication bias was found $(P=0.327-0.455)$. Main effects along with sensitivity and publication bias adjusted results are presented in Table 4. The exercise effect in patients presenting with high mean fatigue levels [54] was slightly greater than that overall observed in overall fatigue $(\mathrm{ES}=$ $-0.4,95 \%$ CI: -0.9 to 0.2 ).

In the dose-response analysis, the meta-regression models did not present significant associations between mode (i.e. resistance training alone vs. resistance-based exercise programs), duration (ranging from 8 to 60 weeks), resistance training weekly volume (ranging from 320 to 975 repetitions) and peak intensity (ranging from 60 to $85 \%$ of 1-RM) with patient-reported fatigue (univariate: $P=$ 0.055-0.988, multivariate: $\mathrm{r}^{2}=100 \%, P=0.375$, Table 5).

\section{Exercise effects on quality of life}

A significant improvement was observed in the quality of life (ES $=0.2,95 \%$ CI: 0.0 to $0.4, P=0.014$ ) in a sample of 447 prostate cancer patients who undertook resistancebased exercise compared to 399 patients in control groups (Fig. 3). This result was maintained after low risk subgroup 
Table 3 Risk of bias of included studies.

\begin{tabular}{|c|c|c|c|c|c|c|}
\hline Outcome & $\begin{array}{l}\text { Randomisation } \\
\text { process }\end{array}$ & $\begin{array}{l}\text { Deviation from } \\
\text { intended interventions }\end{array}$ & $\begin{array}{l}\text { Missing } \\
\text { outcome data }\end{array}$ & $\begin{array}{l}\text { Measurement of the } \\
\text { outcome }\end{array}$ & $\begin{array}{l}\text { Selection of the } \\
\text { reported result }\end{array}$ & Overall bias \\
\hline \multicolumn{7}{|c|}{ Fatigue, $n=14$} \\
\hline Low risk & $14(100 \%)$ & $14(100 \%)$ & $14(100 \%)$ & $14(100 \%)$ & $13(92.9 \%)$ & $13(92.9 \%)$ \\
\hline $\begin{array}{l}\text { Some } \\
\text { concerns }\end{array}$ & 0 & 0 & 0 & 0 & $1(7.1 \%)$ & $1(7.1 \%)$ \\
\hline High risk & 0 & 0 & 0 & 0 & 0 & 0 \\
\hline \multicolumn{7}{|c|}{ Quality of life, $n=15$} \\
\hline Low risk & $14(93.3 \%)$ & $15(100 \%)$ & $15(100 \%)$ & $15(100 \%)$ & $14(93.3 \%)$ & $13(86.7 \%)$ \\
\hline $\begin{array}{l}\text { Some } \\
\text { concerns }\end{array}$ & $1(6.7 \%)$ & 0 & 0 & 0 & $1(6.7 \%)$ & $2(13.3 \%)$ \\
\hline High risk & 0 & 0 & 0 & 0 & 0 & 0 \\
\hline \multicolumn{7}{|c|}{ Depression, $n=4$} \\
\hline Low risk & $3(75.0 \%)$ & $4(100 \%)$ & $4(100 \%)$ & $4(100 \%)$ & $4(100 \%)$ & $3(75.0 \%)$ \\
\hline $\begin{array}{l}\text { Some } \\
\text { concerns }\end{array}$ & $1(25.0 \%)$ & 0 & 0 & 0 & 0 & $1(25.0 \%)$ \\
\hline High risk & 0 & 0 & 0 & 0 & 0 & 0 \\
\hline \multicolumn{7}{|c|}{ Anxiety, $n=3$} \\
\hline Low risk & $2(66.7 \%)$ & $3(100 \%)$ & $3(100 \%)$ & $3(100 \%)$ & $3(100 \%)$ & $2(66.7 \%)$ \\
\hline $\begin{array}{l}\text { Some } \\
\text { concerns }\end{array}$ & $1(33.3 \%)$ & 0 & 0 & 0 & 0 & $1(33.3 \%)$ \\
\hline High risk & 0 & 0 & 0 & 0 & 0 & 0 \\
\hline
\end{tabular}

$n$ number of studies.

Fig. 2 Mean difference effects of resistance-based exercise compared with control on fatigue. Overall and subgroup analyses conducted with a random-effects model. Grey and white circles represent study specific estimates based on risk of bias assessment (Low risk, and some concern or high risk of bias, respectively); diamonds represent pooled estimates of random-effects meta-analysis.

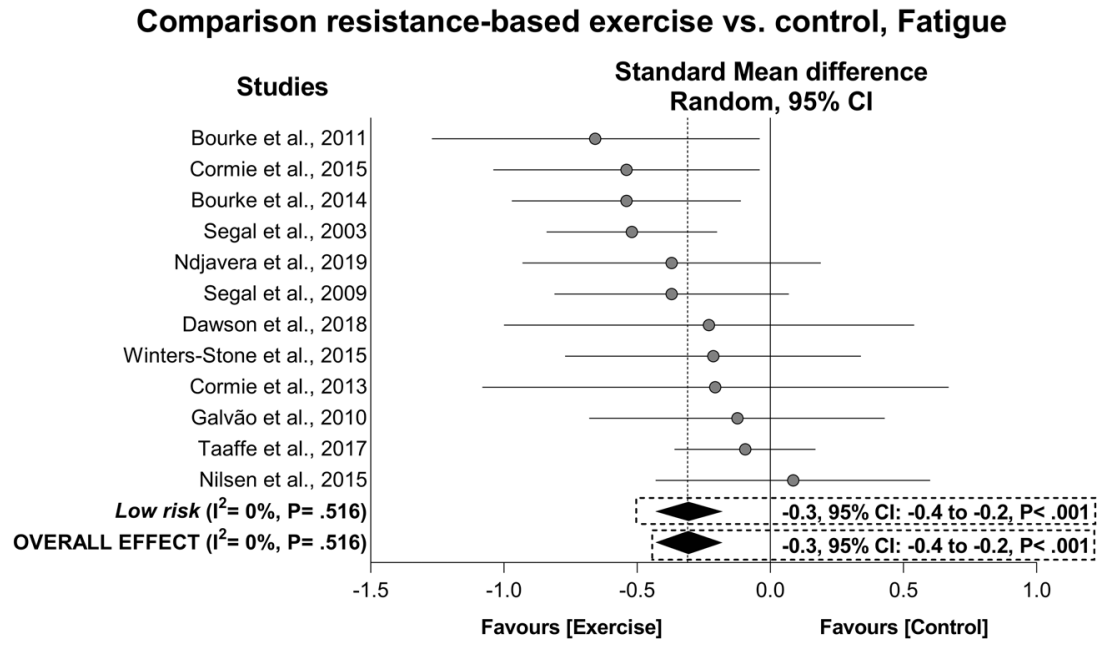

analysis (Table 4). Exercise also resulted in a positive effect of 4.4 pts (95\% CI: 1.7 to 7.2 pts, $P=0.002)$ in FACT-G and 4.8 pts $(95 \% \mathrm{CI}: 3.1$ to 6.5 pts, $P<0.001)$ in the FACT$\mathrm{P}$ with $\mathrm{I}^{2}=0$ and $12 \%$, respectively. Low risk subgroup analysis indicated a positive effect of exercise on FACT-P and FACT-G. In addition, exercise resulted in significant effects in specific components of the SF-36 (i.e. physical functioning, role physical, mental health composite, social functioning and mental health, $P=0.003-0.020)$ as indicated by the low risk subgroup analyses, while effects on the EORTC QLQ-C30 components (i.e. emotional functioning, cognitive functioning, and dyspnoea; $P=$ 0.003-0.020) were observed in the overall and maintained in the subgroup analysis. Outliers were identified in FACTG [50], FACT-P [43], SF-36 $6_{\text {Physical functioning and SF-36 }}$ Mental health composite [49], SF-36 Vitality [6] and EORTC QLQ$\mathrm{C} 30$ Emotional functioning [11] analyses and omitted from the abovementioned results. No publication bias was observed $(P=0.272-0.539)$. The main effects along with sensitivity and publication bias adjusted results are presented in Table 4. The exercise effects in patients presenting with low mean quality of life values [50] were somewhat smaller than 
Table 4 Overall intervention effects on the patient-reported outcomes in prostate cancer patients.

\begin{tabular}{|c|c|c|c|c|c|c|c|}
\hline$\overline{\text { Outcomes }}$ & Analysis & $n$ & Sample & Mean difference & $95 \% \mathrm{CI}$ & $\mathrm{I}^{2}$ & Mean difference $P$ value \\
\hline \multicolumn{8}{|l|}{ Fatigue } \\
\hline \multirow[t]{2}{*}{ Overall $^{\mathrm{a}}$} & $\mathrm{All}^{\mathrm{b}}$ & 12 & 896 & -0.3 & -0.4 to -0.2 & $0 \%$ & $<0.001$ \\
\hline & Low risk ${ }^{\mathrm{b}}$ & 12 & 896 & -0.3 & -0.4 to -0.2 & $0 \%$ & $<0.001$ \\
\hline \multirow[t]{2}{*}{ FACT-F, pts ${ }^{\mathrm{b}}$} & $\mathrm{All}^{\mathrm{b}}$ & 6 & 474 & 3.9 & 2.6 to 5.3 & $0 \%$ & $<0.001$ \\
\hline & Low risk ${ }^{b}$ & 4 & 365 & 4.1 & 2.8 to 5.4 & $0 \%$ & $<0.001$ \\
\hline \multirow[t]{2}{*}{ EORTC QLQ-C30 Fatigue } & All & 5 & 396 & -5.2 & -10.1 to -0.2 & $31 \%$ & 0.040 \\
\hline & Low risk & 5 & 396 & -5.2 & -10.1 to -0.2 & $31 \%$ & 0.040 \\
\hline \multirow[t]{2}{*}{ MFSI-SF } & $\mathrm{All}^{\mathrm{d}}$ & 1 & 20 & -4.2 & -17.6 to 9.2 & - & - \\
\hline & Low risk ${ }^{\mathrm{d}}$ & 1 & 20 & -4.2 & -17.6 to 9.2 & - & - \\
\hline \multirow[t]{2}{*}{ FACIT-Fatigue } & $\mathrm{All}^{\mathrm{d}}$ & 2 & 113 & 3.6 & 1.2 to 6.0 & - & - \\
\hline & Low risk ${ }^{\mathrm{d}}$ & 2 & 113 & 3.6 & 1.2 to 6.0 & - & - \\
\hline \multirow[t]{2}{*}{ BFI } & $\mathrm{All}^{\mathrm{d}}$ & 1 & 26 & -0.8 & -2.6 to 1.0 & - & - \\
\hline & Low risk ${ }^{\mathrm{d}}$ & - & - & - & - & - & - \\
\hline \multirow[t]{2}{*}{ Schwartz Cancer Fatigue Scale } & $\mathrm{All}^{\mathrm{d}}$ & 1 & 51 & 5.5 & -3.1 to 14.0 & - & - \\
\hline & Low risk ${ }^{\mathrm{d}}$ & 1 & 51 & 5.5 & -3.1 to 14.0 & - & - \\
\hline \multicolumn{8}{|l|}{ Quality of life } \\
\hline \multirow[t]{2}{*}{ Overall $^{\mathrm{a}}$} & $\mathrm{All}^{\mathrm{b}}$ & 12 & 846 & 0.2 & 0.0 to 0.4 & $28 \%$ & 0.014 \\
\hline & Low risk ${ }^{\mathrm{b}}$ & 11 & 716 & 0.2 & 0.0 to 0.4 & $32 \%$ & 0.018 \\
\hline \multirow[t]{2}{*}{ FACT-G } & $\mathrm{All}^{\mathrm{b}}$ & 4 & 187 & 4.4 & 1.7 to 7.2 & $0 \%$ & 0.002 \\
\hline & Low risk ${ }^{\mathrm{b}}$ & 3 & 150 & 4.7 & 1.7 to 7.8 & $0 \%$ & 0.002 \\
\hline \multirow[t]{2}{*}{ FACT-P } & $\mathrm{All}^{\mathrm{b}}$ & 6 & 396 & 4.8 & 3.1 to 6.5 & $12 \%$ & $<0.001$ \\
\hline & Low risk ${ }^{\mathrm{b}}$ & 5 & 359 & 6.3 & 3.8 to 8.7 & $0 \%$ & $<0.001$ \\
\hline \multirow[t]{2}{*}{ SF-36 Physical health composite } & All & 5 & 293 & 0.8 & -0.7 to 2.3 & $45 \%$ & 0.291 \\
\hline & Low risk & 5 & 293 & 0.8 & -0.7 to 2.3 & $45 \%$ & 0.291 \\
\hline \multirow[t]{2}{*}{ SF-36 Physical functioning } & $\mathrm{All}^{\mathrm{b}}$ & 5 & 287 & 1.9 & 0.7 to 3.2 & $0 \%$ & 0.003 \\
\hline & Low risk & 5 & 287 & 1.9 & 0.7 to 3.2 & $0 \%$ & 0.003 \\
\hline \multirow[t]{2}{*}{ SF-36 Role physical } & All & 4 & 239 & 2.2 & 0.3 to 4.2 & $0 \%$ & 0.025 \\
\hline & Low risk & 4 & 239 & 2.2 & 0.3 to 4.2 & $0 \%$ & 0.025 \\
\hline \multirow[t]{2}{*}{ SF-36 Bodily pain } & All & 4 & 239 & -0.2 & -2.5 to 2.1 & $16 \%$ & 0.843 \\
\hline & Low risk & 4 & 239 & -0.2 & -2.5 to 2.1 & $16 \%$ & 0.843 \\
\hline \multirow[t]{2}{*}{ SF-36 General health } & All & 4 & 239 & 1.8 & -0.5 to 4.0 & $30 \%$ & 0.131 \\
\hline & Low risk & 4 & 239 & 1.8 & -0.5 to 4.0 & $30 \%$ & 0.131 \\
\hline \multirow[t]{2}{*}{ SF-36 Mental health composite } & $\mathrm{All}^{\mathrm{b}}$ & 4 & 239 & 2.9 & 1.2 to 4.7 & $0 \%$ & 0.001 \\
\hline & Low risk ${ }^{b}$ & 4 & 239 & 2.9 & 1.2 to 4.7 & $0 \%$ & 0.001 \\
\hline \multirow[t]{2}{*}{ SF-36 Vitality } & $\mathrm{All}^{\mathrm{b}, \mathrm{c}}$ & 6 & 450 & 0.2 & -0.7 to 1.1 & $21 \%$ & 0.655 \\
\hline & Low risk ${ }^{\mathrm{b}}$ & 6 & 450 & 0.2 & -0.7 to 1.1 & $21 \%$ & 0.655 \\
\hline \multirow[t]{2}{*}{ SF-36 $6_{\text {Social functioning }}$} & All & 4 & 239 & 4.7 & 2.7 to 6.6 & $0 \%$ & $<0.001$ \\
\hline & Low risk & 4 & 239 & 4.7 & 2.7 to 6.6 & $0 \%$ & $<0.001$ \\
\hline \multirow[t]{2}{*}{ SF-36 $6_{\text {Role emotional }}$} & All & 4 & 239 & 0.9 & -1.0 to 2.8 & $0 \%$ & 0.371 \\
\hline & Low risk & 4 & 239 & 0.9 & -1.0 to 2.8 & $0 \%$ & 0.371 \\
\hline SF-36 Mental Health & All & 4 & 239 & 2.4 & 0.8 to 4.0 & $0 \%$ & 0.004 \\
\hline & Low risk & 4 & 239 & 2.4 & 0.8 to 4.0 & $0 \%$ & 0.004 \\
\hline EORTC QLQ-C30 Global & All & 4 & 310 & -0.1 & -5.1 to 4.9 & $44 \%$ & 0.980 \\
\hline & Low risk & 3 & 180 & -1.3 & -8.5 to 6.0 & $50 \%$ & 0.731 \\
\hline EORTC QLQ-C30 Physical functioning & $\mathrm{All}^{\mathrm{c}}$ & 4 & 310 & 1.9 & -0.6 to 4.5 & $35 \%$ & 0.138 \\
\hline & Low risk & 3 & 180 & 3.1 & -0.3 to 6.4 & $27 \%$ & 0.073 \\
\hline EORTC QLQ-C30 & All & 4 & 310 & 5.0 & -0.6 to 10.6 & $44 \%$ & 0.080 \\
\hline
\end{tabular}


Table 4 (continued)

\begin{tabular}{|c|c|c|c|c|c|c|c|}
\hline Outcomes & Analysis & $n$ & Sample & Mean difference & $95 \% \mathrm{CI}$ & $\mathrm{I}^{2}$ & Mean difference $P$ value \\
\hline \multirow{3}{*}{ EORTC QLQ-C30 Emotional functioning } & Low risk & 3 & 106 & 8.5 & -0.2 to 17.3 & $45 \%$ & 0.057 \\
\hline & $\mathrm{All}^{\mathrm{b}}$ & 3 & 180 & 6.1 & 1.0 to 11.2 & $5 \%$ & 0.020 \\
\hline & Low risk & 3 & 180 & 6.1 & 1.0 to 11.2 & $5 \%$ & 0.020 \\
\hline \multirow[t]{2}{*}{ EORTC QLQ-C30 $0_{\text {Cognitive functioning }}$} & All & 4 & 310 & 4.9 & 1.7 to 8.1 & $39 \%$ & 0.003 \\
\hline & Low risk & 3 & 180 & 6.2 & 0.5 to 11.9 & $29 \%$ & 0.034 \\
\hline \multirow[t]{2}{*}{ EORTC QLQ-C30 ${ }_{\text {Social functioning }}$} & All & 4 & 310 & 3.4 & -1.7 to 8.4 & $0 \%$ & 0.190 \\
\hline & Low risk & 3 & 180 & 3.5 & -2.9 to 10.0 & $0 \%$ & 0.282 \\
\hline \multirow[t]{2}{*}{ EORTC QLQ-C $30_{\text {Nausea and vomiting }}$} & All & 3 & 180 & -1.8 & -4.1 to 0.5 & $14 \%$ & 0.128 \\
\hline & Low risk & 3 & 180 & -1.8 & -4.1 to 0.5 & $14 \%$ & 0.128 \\
\hline \multirow[t]{2}{*}{ EORTC QLQ-C30 Pain } & All & 3 & 180 & -4.3 & -11.6 to 3.1 & $21 \%$ & 0.258 \\
\hline & Low risk & 3 & 180 & -4.3 & -11.6 to 3.1 & $21 \%$ & 0.258 \\
\hline \multirow[t]{2}{*}{ EORTC QLQ-C30 } & All & 3 & 180 & -8.8 & -16.0 to -1.6 & $0 \%$ & 0.016 \\
\hline & Low risk & 3 & 180 & -8.8 & -16.0 to -1.6 & $0 \%$ & 0.016 \\
\hline \multirow[t]{2}{*}{ EORTC QLQ-C30 Insomnia } & All & 3 & 180 & -5.0 & -15.6 to 5.6 & $32 \%$ & 0.358 \\
\hline & Low risk & 3 & 180 & -5.0 & -15.6 to 5.6 & $32 \%$ & 0.358 \\
\hline \multirow[t]{2}{*}{ EORTC QLQ-C30 Appetite loss } & All & 3 & 180 & -0.5 & -4.5 to 3.4 & $6 \%$ & 0.789 \\
\hline & Low risk & 3 & 180 & -0.5 & -4.5 to 3.4 & $6 \%$ & 0.789 \\
\hline \multirow[t]{2}{*}{ EORTC QLQ-C30 ${ }_{\text {Constipation }}$} & All & 3 & 180 & 1.5 & -3.7 to 6.8 & $0 \%$ & 0.567 \\
\hline & Low risk & 3 & 180 & 1.5 & -3.7 to 6.8 & $0 \%$ & 0.567 \\
\hline \multirow[t]{2}{*}{ EORTC QLQ-C30 Diarrhoea $_{\text {}}$} & All & 3 & 180 & 0.8 & -9.3 to 10.8 & $56 \%$ & 0.878 \\
\hline & Low risk & 3 & 180 & 0.8 & -9.3 to 10.8 & $56 \%$ & 0.878 \\
\hline \multirow[t]{2}{*}{ EORTC QLQ-C30 Finance } & $\mathrm{All}^{\mathrm{d}}$ & 2 & 107 & -0.9 & -7.7 to 5.9 & - & - \\
\hline & Low risk ${ }^{\mathrm{d}}$ & 2 & 107 & -0.9 & -7.7 to 5.9 & - & - \\
\hline \multicolumn{8}{|l|}{ Depression } \\
\hline \multirow[t]{2}{*}{ Overall $^{\mathrm{a}}$} & All & 4 & 239 & -0.2 & -0.5 to 0.0 & $0 \%$ & 0.091 \\
\hline & Low risk & 3 & 109 & -0.3 & -0.7 to 0.0 & $0 \%$ & 0.077 \\
\hline \multirow[t]{2}{*}{ CES-D } & $\mathrm{All}^{\mathrm{d}}$ & 2 & 156 & -1.9 & -3.8 to -0.1 & - & - \\
\hline & Low risk ${ }^{\mathrm{d}}$ & 1 & 26 & -2.8 & -8.9 to 3.3 & - & - \\
\hline \multirow[t]{2}{*}{ BSI-18 Depression } & $\mathrm{All}^{\mathrm{d}}$ & 2 & 83 & -1.2 & -2.1 to -0.2 & - & - \\
\hline & Low risk $^{\mathrm{d}}$ & 2 & 83 & -1.2 & -2.1 to -0.2 & - & - \\
\hline \multicolumn{8}{|l|}{ Anxiety } \\
\hline \multirow[t]{2}{*}{ Overall $^{\mathrm{a}}$} & All & 3 & 212 & -0.3 & -0.5 to 0.0 & $0 \%$ & 0.071 \\
\hline & Low risk ${ }^{\mathrm{d}}$ & 2 & 83 & -0.1 & -0.5 to 0.3 & - & - \\
\hline \multirow[t]{2}{*}{ BSI-18 $8_{\text {Anxiety }}$} & $\mathrm{All}^{\mathrm{d}}$ & 2 & 83 & -0.5 & -1.2 to 0.2 & - & - \\
\hline & Low risk ${ }^{\mathrm{d}}$ & 2 & 83 & -0.5 & -1.2 to 0.2 & - & - \\
\hline \multirow[t]{2}{*}{ MAX-PC } & $\mathrm{All}^{\mathrm{d}}$ & 1 & 129 & 2.5 & 0.4 to 4.6 & - & - \\
\hline & Low risk ${ }^{\mathrm{d}}$ & - & - & - & - & - & - \\
\hline
\end{tabular}

Questionnaires reverse scaled (High scores-Less fatigue).

BFI Brief Fatigue Inventory, BSI-18 Brief Symptom Inventory-18, CES-D Center for Epidemiologic Studies-Depression Scale, EORTC QLQC30 European Organisation for Research and Treatment of Cancer Quality of Life Questionnaire C30, FACIT Functional Assessment of Chronic Illness Therapy, FACT-F Functional Assessment of Cancer Therapy-Fatigue, FACT-G Functional Assessment of Cancer Therapy-General, FACT-P Functional Assessment of Cancer Therapy-Prostate, MAX-PC Memorial Anxiety Scale for Prostate Cancer, MFSI-SF Multidimensional Fatigue Symptom Inventory-Short Form, $n$ number of comparisons, $S F$-36 36-Item Short-Form Health Survey.

${ }^{\mathrm{a}}$ Analysis performed using standardized mean difference effect.

${ }^{\mathrm{b}}$ Adjustment after sensitivity analysis omitting one study at a time.

'Trim-and-fill adjustment after significant effect of publication bias in Egger's test $(P<0.1)$.

${ }^{\mathrm{d}}$ Insufficient data for analysis. 


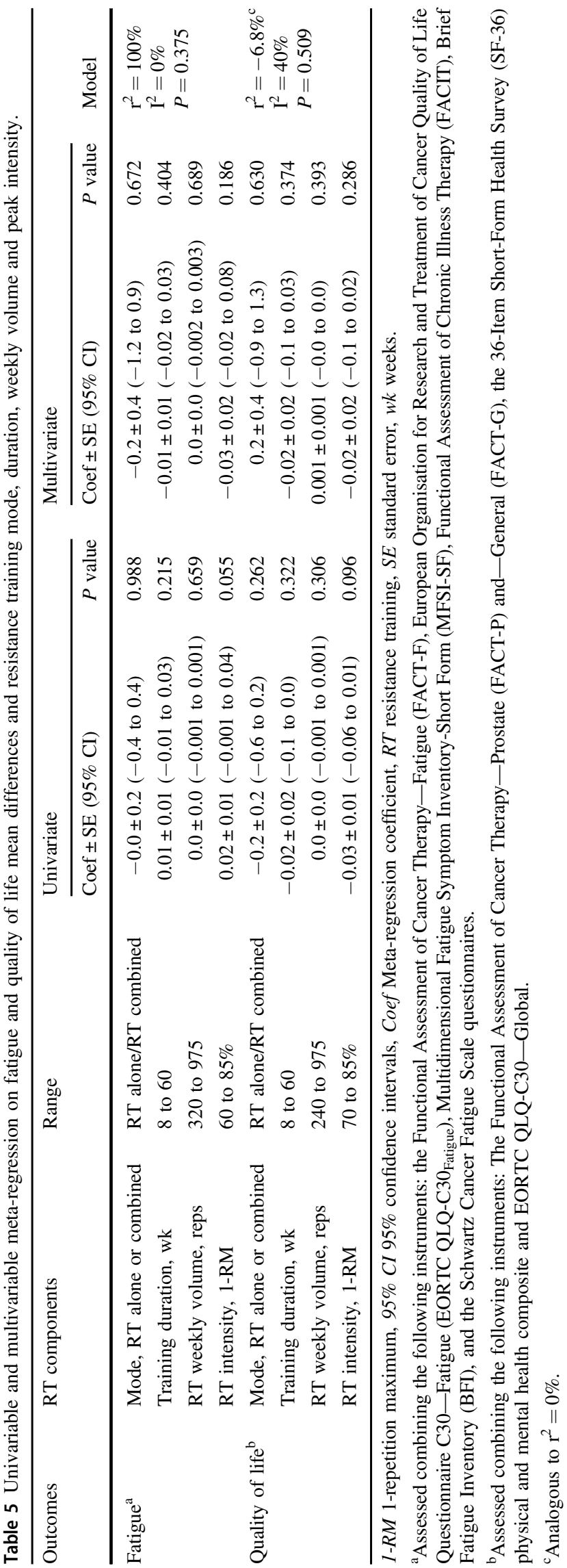

that overall observed in overall quality of life $(\mathrm{ES}=0.1$, 95\% CI: -0.4 to 0.6 ).

In the dose-response analysis, the meta-regression models did not present significant associations between mode (i.e. resistance training alone vs. resistance-based exercise programs), duration (ranging from 8 to 60 weeks), resistance training weekly volume (ranging from 240 to 975 repetitions) and peak intensity (ranging from 70 to $85 \%$ of 1-RM) with effects on patient-reported quality of life (univariate: $P=0.096-0.322$, multivariate: $\mathrm{r}^{2}=-6.8 \%, P=$ 0.509 , Table 5).

\section{Exercise effects on depression and anxiety symptoms}

There was no significant exercise effect for overall depression and overall anxiety $(\mathrm{ES}=-0.2,95 \% \mathrm{CI}:-0.5$ to $0.0 . P=0.091$ and $\mathrm{ES}=-0.3,95 \% \mathrm{CI}:-0.5$ to $0.0, P=$ 0.071 , respectively; Table 4 and Fig. 4). The heterogeneity was $\mathrm{I}^{2}=0 \%$ with no effect of publication bias $(P=$ $0.717-0.815$ ). Effects on overall depression were maintained in the subgroup analysis, while not conducted on anxiety given the small number of studies included. There were insufficient data for the dose-response analysis in depression and anxiety outcomes.

\section{Discussion}

The present review examined the resistance training effect and dose-response on common patient-reported outcomes in prostate cancer patients. The main findings were: (1) supervised resistance exercise produced significant positive benefits on overall fatigue and quality of life whether undertaken as a sole exercise mode or combined with other exercise modes; and (2) the beneficial effects on fatigue and quality of life were independent of the prescribed exercise volume and intensity undertaken. In addition, exercise effects on overall depression and anxiety outcomes were positive, although not significant. These results are clinically relevant and demonstrate the potential to use a lower weekly volume and moderate intensity exercise as a strategy to improve quality of life and reduce cancer-related fatigue during and following active treatment.

Fatigue is one of the most reported symptoms in prostate cancer patients [3]. Considering its multifactorial nature, fatigue is examined via physical, social, emotional and functional wellbeing aspects in several questionnaires. In the present review, a positive exercise effect was indicated for overall fatigue and there were increases beyond the minimally important clinically difference in the FACT-F and EORTC QLQ-C30 Fatigue, a result sustained in the low risk randomised controlled trials. However, it is important to note that patients 
Fig. 3 Mean difference effects of resistance-based exercise compared with control on quality of life. Overall and subgroup analyses conducted with a random-effects model. Grey and white circles represent study specific estimates based on risk of bias assessment (Low risk, and some concern or high risk of bias, respectively); diamonds represent pooled estimates of random-effects meta-analysis.

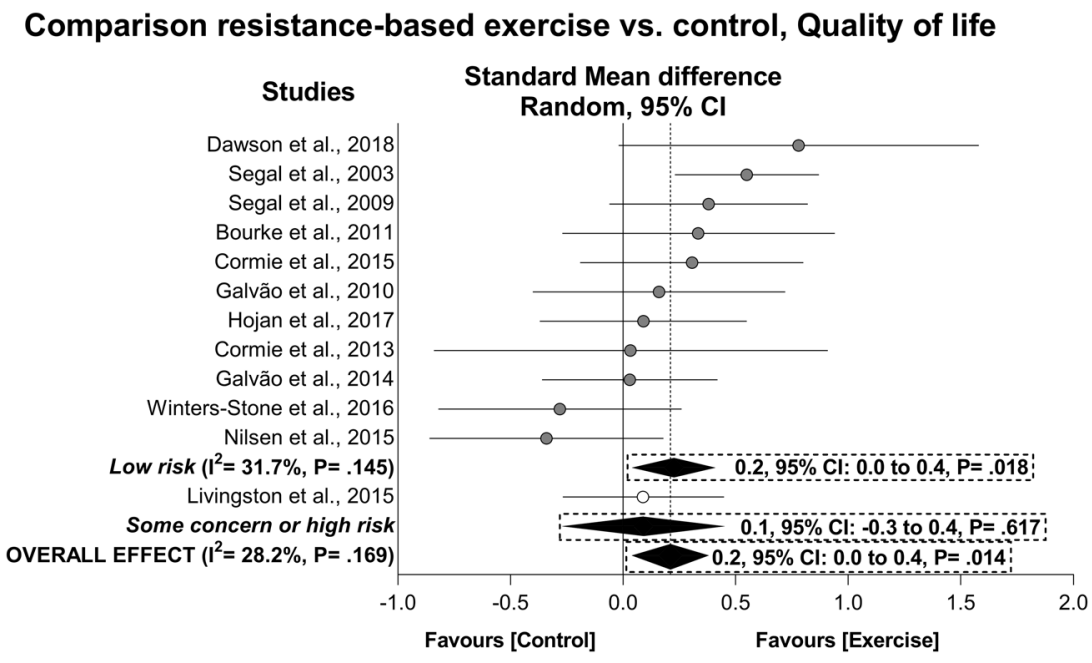

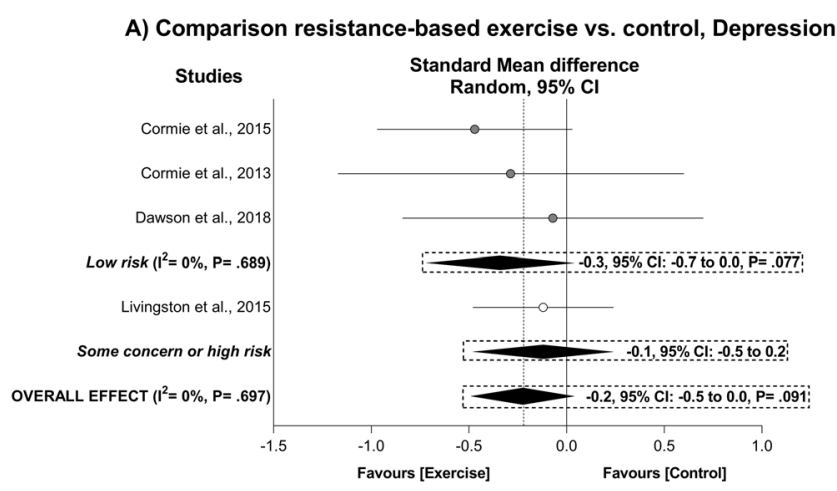

Fig. 4 Mean difference effects of resistance-based exercise compared with control on depression (A) and anxiety (B). Overall and subgroup analyses conducted with a random-effects model. Grey and white circles represent study specific estimates based on risk of bias

included in the present analysis generally presented low baseline levels of fatigue which may indicate that patients with greater fatigue may derive a greater benefit from exercise [8]. Previous studies [8, 15, 55] are in accordance with the present analysis, demonstrating changes of $\sim 3$ pts in the EORTC QLQ-C30 Fatigue [8] moderated by higher baseline fatigue levels $[8,55]$. Thus, the present findings suggest that supervised resistance-based programs can reduce levels of fatigue in prostate cancer patients at various disease stages and it may well be that patients with high baseline levels of fatigue may experience greater improvements as previously reported [8, 55]. Furthermore, the lack of association between resistance training dosage and its effects on overall fatigue also indicates the potential of exercise medicine using a lower exercise dosage to manage cancer-related fatigue. The benefits to using a low dosage of resistance training (e.g. less repetitions per exercise at a moderate to high intensity) appears to be regardless of the intervention duration as shortterm programs (8 weeks) produced similar reductions in

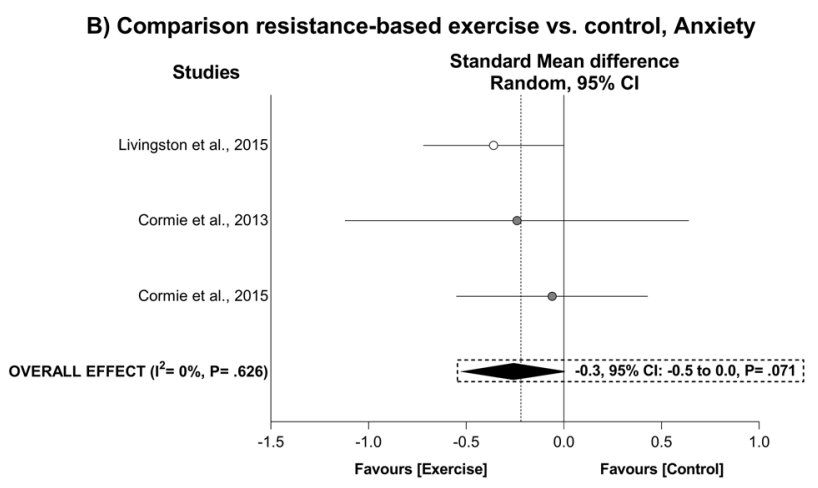

assessment (Low risk, and some concern or high risk of bias, respectively); diamonds represent pooled estimates of random-effects meta-analysis.

overall fatigue to that achieved by longer duration interventions (e.g. 60 weeks) in prostate cancer patients at different treatment stages. Finally, our results also demonstrate similar effects between different exercise modes as denoted by the nonsignificant univariate meta-regression model. This result agrees with a previous study [56] showing that resistance, aerobic or combined resistance and aerobic exercise promotes similar effects on cancer-related fatigue in cancer patients $(-0.21,-0.23$ and $-0.26 \mathrm{SMD}$, respectively) and demonstrates the potential use of a low dosage even when resistance exercise is prescribed as a single mode of exercise in men with prostate cancer.

Overall quality of life was significantly improved in prostate cancer patients who undertook supervised resistancebased exercise programs. Our results are in accordance with meta-analyses undertaken in healthy older adults [57] and those with cancer [58, 59] where quality of life was assessed using the SF-36 and FACT questionnaires. Furthermore, a low resistance training dosage may culminate in comparable 
effects to that achieved by higher dosages in quality of life as noted by the nonsignificant meta-regression models. These results concur with those of Sweegers et al. [59] who found no difference in quality of life in cancer patients with varying weekly exercise volumes and energy expenditures during or following treatment. Importantly, the present findings suggest that less repetitions per exercise at a moderate to high intensity is sufficient to improve quality of life in prostate cancer patients, which is smaller than the dosage currently proposed for this outcome [12]. Therefore, these results are of importance for prostate cancer patients in different treatment phases as it reduces the time required (and effort/energy expenditure required) for exercise, which may permit higher attendance and compliance along with sustained benefits in longer term exercise programs.

The present analysis essentially included a small number of studies involving non-depressed men with prostate cancer as observed by the baseline values reported [10, 11, 45, 52]. Despite comparable effects to those observed in fatigue and quality of life, the exercise effects on depression symptoms only approached statistical significance, presenting similar effect sizes to studies in other cancer populations [60] but smaller than that observed when different clinical populations are pooled [61]. As a result, despite the overall significant association between resistance exercise and reduced depressive symptoms observed previously [60, 61], larger and more rigorous studies are necessary to clarify the effect of resistance-based exercise on depression in men with prostate cancer and include patients with existing depression. In addition, whether combining resistance and aerobic exercise accrues superior effects than resistance training alone is yet to be determined.

The use of exercise medicine is important for prostate cancer patients given the anxieties associated living with a cancer diagnosis and fears regarding its progression [4, 5]. We did not observe significant anxiolytic effects of resistance-based exercise programs in prostate cancer patients, which contrasts with studies in older adults [62], breast cancer patients [63] and other groups of cancer patients [64]. The reasons for such differences could be related to the few studies included in the analysis and apparently low baseline anxiety values of men in these studies. However, given this outcome approached statistical significance $(P=0.071)$, it is possible to suggest that exercise may in some cases counter anxiety, especially in those patients with greater anxiety levels. This result is important given the relatively high prevalence of this symptom across the treatment spectrum [5], and the association of anxiety with poorer surgical outcomes [65]. Moreover, the number of studies included also precluded further analysis regarding the exercise minimal dosage or mode. Thus, it is not possible to examine if low dosages or the prescription of resistance training alone may provide meaningful effects in this outcome as observed in fatigue and quality of life, or even in other types of cancer [63, 64].

The strengths of the present study include the large number of trials and participants assessing different patient-report outcomes, and the assessment of low risk studies. However, there are also some limitations which are worthy of comment. First, there were insufficient data to perform dose-response analyses on the depression and anxiety outcomes. These were both secondary outcomes in our analysis and in all exercise trials where the recruitment was not based on depression or anxiety levels. Studies designed to directly investigate these outcomes in those with depression and anxiety are required to determine the efficacy of exercise and its dosage in this patient/survivorship group. Second, we used prescribed instead of the complied exercise dosage given that this is predominantly reported in the studies analysed. However, reporting of complied dosage $[12,66]$ in future studies will assist with better defining the upper and lower exercise prescription thresholds. Third, the nature of supervised group sessions may be considered a potential factor in some of the included studies. Participants in supervised exercise group sessions are likely to share experiences related to treatment as well as develop camaraderie during the exercise program [8] and, consequently, this may contribute to additional benefits in these individual studies. Lastly, although most patients included were on ADT, the lower heterogeneity within the analyses may indicate that the response is quite similar following treatment.

Establishing the minimal-dose approach to enhance patient-reported outcomes is challenging in the field of exercise oncology. As far as are aware, this is the first study to examine the resistance training dose-response on patientreport outcomes in prostate cancer patients. Our findings suggest that a low dosage (e.g. less repetitions per exercise undertaken at a moderate to high intensity), less than that proposed in the latest exercise guideline for cancer patients [12], is sufficient to induce meaningful benefits for fatigue and quality of life in patients during or following active treatment. Furthermore, the present results regarding depression and anxiety outcomes are also promising, indicating the potential use of resistance-based training to avoid further psychological distress during and following active treatment.

Acknowledgements PL is supported by the National Health and Medical Research Council (NHMRC) Centre of Research Excellence (CRE) in Prostate Cancer Survivorship Scholarship. DAG and RUN are funded by a NHMRC CRE in Prostate Cancer Survivorship. The results of the study are presented clearly, honestly, without fabrication, falsification or inappropriate data manipulation.

Funding Sponsors had no involvement in the study design, analysis or interpretation of data, manuscript writing and decision to submit the manuscript for publication. 
Author contributions Substantial contributions to the conception and design of the work were done by PL, DRT, RUN and DAG. The work draft and revision, as well as the approval of the final version, were done by PL, DRT, RUN, LMB and DAG. In addition, all aspects of this work related to the accuracy or integrity were ensured by PL, DRT, RUN, LMB and DAG.

\section{Compliance with ethical standards}

Conflict of interest The authors declare that they have no conflict of interest.

Publisher's note Springer Nature remains neutral with regard to jurisdictional claims in published maps and institutional affiliations.

Open Access This article is licensed under a Creative Commons Attribution 4.0 International License, which permits use, sharing, adaptation, distribution and reproduction in any medium or format, as long as you give appropriate credit to the original author(s) and the source, provide a link to the Creative Commons license, and indicate if changes were made. The images or other third party material in this article are included in the article's Creative Commons license, unless indicated otherwise in a credit line to the material. If material is not included in the article's Creative Commons license and your intended use is not permitted by statutory regulation or exceeds the permitted use, you will need to obtain permission directly from the copyright holder. To view a copy of this license, visit http://creativecommons. org/licenses/by/4.0/.

\section{References}

1. D'Amico AV, Chen MH, Renshaw AA, Loffredo M, Kantoff PW. Androgen suppression and radiation vs radiation alone for prostate cancer: a randomized trial. JAMA. 2008;23:289-95.

2. Nguyen PL, Alibhai SM, Basaria S, D'Amico AV, Kantoff PW, Keating NL, et al. Adverse effects of androgen deprivation therapy and strategies to mitigate them. Eur Urol. 2015;67:825-36.

3. Storey DJ, McLaren DB, Atkinson MA, Butcher I, Frew LC, Smyth JF, et al. Clinically relevant fatigue in men with hormonesensitive prostate cancer on long-term androgen deprivation therapy. Ann Oncol. 2012;23:1542-9.

4. Dinh KT, Yang DD, Nead KT, Reznor G, Trinh QD, Nguyen PL. Association between androgen deprivation therapy and anxiety among 78000 patients with localized prostate cancer. Int J Urol. 2017:24:743-8.

5. Watts S, Leydon G, Birch B, Prescott P, Lai L, Eardley S, et al. Depression and anxiety in prostate cancer: a systematic review and meta-analysis of prevalence rates. BMJ Open. 2014;4:e003901.

6. Galvão DA, Taaffe DR, Spry N, Joseph D, Newton RU. Combined resistance and aerobic exercise program reverses muscle loss in men undergoing androgen suppression therapy for prostate cancer without bone metastases: a randomized controlled trial. J Clin Oncol. 2010;28:340-7.

7. Galvão DA, Spry N, Denham J, Taaffe DR, Cormie P, Joseph D, et al. A multicentre year-long randomised controlled trial of exercise training targeting physical functioning in men with prostate cancer previously treated with androgen suppression and radiation from TROG 03.04 RADAR. Eur Urol. 2014;65:856-64.

8. Taaffe DR, Newton RU, Spry N, Joseph D, Chambers SK, Gardiner RA, et al. Effects of different exercise modalities on fatigue in prostate cancer patients undergoing androgen deprivation therapy: a year-long randomised controlled trial. Eur Urol. 2017;72:293-9.
9. Taaffe DR, Buffart LM, Newton RU, Spry N, Denham J, Joseph $\mathrm{D}$, et al. Time on androgen deprivation therapy and adaptations to exercise: Secondary analysis from a 12-month randomized controlled trial in men with prostate cancer. BJU Int. 2018;121:194-202.

10. Cormie P, Galvão DA, Spry N, Joseph D, Chee R, Taaffe DR, et al. Can supervised exercise prevent treatment toxicity in patients with prostate cancer initiating androgen-deprivation therapy: a randomised controlled trial. BJU Int. 2015;115:256-66.

11. Livingston PM, Craike MJ, Salmon J, Courneya KS, Gaskin CJ, Fraser SF, et al. Effects of a clinician referral and exercise program for men who have completed active treatment for prostate cancer: a multicenter cluster randomized controlled trial (ENGAGE). Cancer. 2015;121:2646-54.

12. Campbell KL, Winters-Stone KM, Wiskemann J, May AM, Schwartz AL, Courneya KS, et al. Exercise guidelines for cancer survivors: consensus statement from international multidisciplinary roundtable. Med Sci Sports Exerc. 2019;51:2375-90.

13. Norris MK, Bell GJ, North S, Courneya KS. Effects of resistance training frequency on physical functioning and quality of life in prostate cancer survivors: a pilot randomized controlled trial. Prostate Cancer Prostatic Dis. 2015;18:281-7.

14. Bourke L, Smith D, Steed L, Hooper R, Carter A, Catto J, et al. Exercise for men with prostate cancer: a systematic review and meta-analysis. Eur Urol. 2016;69:693-703.

15. Chen Z, Zhang Y, Lu C, Zeng H, Schumann M, Cheng S. Supervised physical training enhances muscle strength but not muscle mass in prostate cancer patients undergoing androgen deprivation therapy: a systematic review and meta-analysis. Front Physiol. 2019;10:843.

16. Keilani M, Hasenoehrl T, Baumann L, Ristl R, Schwarz M, Marhold M, et al. Effects of resistance exercise in prostate cancer patients: a meta-analysis. Support Care Cancer. 2017;25: 2953-68.

17. Yang B, Wang J. Effects of exercise on cancer-related fatigue and quality of life in prostate cancer patients undergoing androgen deprivation therapy: a meta-analysis of randomized clinical trials. Chin Med Sci J. 2017;32:13-21.

18. Ying M, Zhao R, Jiang D, Gu S, Li M. Lifestyle interventions to alleviate side effects on prostate cancer patients receiving androgen deprivation therapy: a meta-analysis. Jpn J Clin Oncol. 2018;48:827-34.

19. Yunfeng G, Weiyang H, Xueyang H, Yilong H, Xin G. Exercise overcome adverse effects among prostate cancer patients receiving androgen deprivation therapy: an update meta-analysis. Medicine (Baltim). 2017;96:e7368.

20. Liberati A, Altman DG, Tetzlaff J, Mulrow C, Gøtzsche PC, Ioannidis JP, et al. The PRISMA statement for reporting systematic reviews and meta-analyses of studies that evaluate healthcare interventions: explanation and elaboration. BMJ. 2009;339:b2700.

21. Page MJ, McKenzie JE, Bossuyt PM, Boutron I, Hoffmann T, Mulrow $\mathrm{CD}$, et al. Mapping of reporting guidance for systematic reviews and meta-analyses generated a comprehensive item bank for future reporting guidelines. J Clin Epidemiol. 2020;118:60-68.

22. Furlan AD, Pennick V, Bombardier C, van Tulder M, Editorial Board, Cochrane Back Review Group. 2009 updated method guidelines for systematic reviews in the Cochrane Back Review Group. Spine (Philos Pa 1976). 2009;34:1929-41.

23. Sterne JAC, Savović J, Page MJ, Elbers RG, Blencowe NS, Boutron I, et al. RoB 2: a revised tool for assessing risk of bias in randomised trials. BMJ. 2019;366:14898.

24. Yellen SB, Cella DF, Webster K, Blendowski C, Kaplan E. Measuring fatigue and other anemia-related symptoms with the 
Functional Assessment of Cancer Therapy (FACT) measurement system. J Pain Symptom Manag. 1997;13:63-74.

25. Knobel H, Loge JH, Brenne E, Fayers P, Hjermstad MJ, Kaasa S. The validity of EORTC QLQ-C30 fatigue scale in advanced cancer patients and cancer survivors. Palliat Med. 2003;17:664-72.

26. Stein KD, Jacobsen PB, Blanchard CM, Thors C. Further validation of the multidimensional fatigue symptom inventory-short form. J Pain Symptom Manag. 2004;27:14-23.

27. Webster K, Cella D, Yost K. The functional assessment of chronic illness therapy (FACIT) measurement system: Properties, applications, and interpretation. Health Qual Life Outcomes. 2003;1:79.

28. Mendoza T, Wang XS, Cleeland CS, Morrissey M, Johnson BA, Wendt JK, et al. The rapid assessment of fatigue severity in cancer patients: use of the Brief Fatigue Inventory. Cancer. 1999;85:1186-96.

29. Schwartz AL. The Schwartz cancer fatigue scale: testing reliability and validity. Oncol Nurs Forum. 1998;25:711-7.

30. Esper P, Mo F, Chodak G, Sinner M, Cella D, Pienta KJ. Measuring quality of life in men with prostate cancer using the functional assessment of cancer therapy-prostate instrument. Urology. 1997;50:920-8.

31. Gandek B, Ware JE. Translating functioning and well-being: international quality of life assessment (IQOLA) project studies of the SF-36 health survey. J Clin Epidemiol. 1998;51:891-1214.

32. Aaronson NK, Ahmedzai S, Bergman B, Bullinger M, Cull A, Duez NJ, et al. The European Organization for Research and Treatment of Cancer QLQ-C30: a quality-of-life instrument for use in international clinical trials in oncology. J Natl Cancer Inst. 1993;85:365-76.

33. Radloff LS. The CES-D scale: a self-report depression scale for research in the general population. Appl Psychol Meas. 1977;1:385-401.

34. Derogatis LR. Brief Symptom Inventory (BSI)-18: Administration, scoring and procedures manual. Minneapolis: NCS Pearson; 2001.

35. Roth AJ, Rosenfeld B, Kornblith AB, Gibson C, Scher HI, Curley-Smart T, et al. The memorial anxiety scale for prostate cancer: validation of a new scale to measure anxiety in men with with prostate cancer. Cancer. 2003;97:2910-8.

36. Higgins JPT, Thomas J, Chandler J, Cumpston M, Li T, Page MJ, et al. Cochrane handbook for systematic reviews of interventions version 6.0 (updated July 2019). Cochrane, 2019.

37. DerSimonian R, Laird N. Meta-analysis in clinical trials. Control Clin Trials. 1986;7:177-88.

38. Cohen J. Statistical power analysis. Curr Dir Psychol Sci. 1992;1:98-101.

39. Higgins JP, Thompson SG, Deeks JJ, Altman DG. Measuring inconsistency in meta-analyses. BMJ. 2003;327:557-60.

40. Peters JL, Sutton AJ, Jones DR, Abrams KR, Rushton L. Contourenhanced meta-analysis funnel plots help distinguish publication bias from other causes of asymmetry. $\mathrm{J}$ Clin Epidemiol. 2008;61:991-6.

41. Duval S, Tweedie R. Trim and fill: a simple funnel-plot-based method of testing and adjusting for publication bias in metaanalysis. Biometrics. 2000;56:455-63.

42. Segal RJ, Reid RD, Courneya KS, Malone SC, Parliament MB, Scott CG, et al. Resistance exercise in men receiving androgen deprivation therapy for prostate cancer. J Clin Oncol. 2003;21:1653-9.

43. Segal RJ, Reid RD, Courneya KS, Sigal RJ, Kenny GP, Prud'Homme DG, et al. Randomized controlled trial of resistance or aerobic exercise in men receiving radiation therapy for prostate cancer. J Clin Oncol. 2009;27:344-51.
44. Bourke L, Doll H, Crank H, Daley A, Rosario D, Saxton JM. Lifestyle intervention in men with advanced prostate cancer receiving androgen suppression therapy: a feasibility study. Cancer Epidemiol Biomark Prev. 2011;20:647-57.

45. Cormie P, Newton RU, Spry N, Joseph D, Taaffe DR, Galvão DA. Safety and efficacy of resistance exercise in prostate cancer patients with bone metastases. Prostate Cancer Prostatic Dis. 2013;16:328-35.

46. Bourke L, Gilbert S, Hooper R, Steed LA, Joshi M, Catto JW, et al. Lifestyle changes for improving disease-specific quality of life in sedentary men on long-term androgen-deprivation therapy for advanced prostate cancer: a randomised controlled trial. Eur Urol. 2014;65:865-72.

47. Winters-Stone KM, Dieckmann N, Maddalozzo GF, Bennett JA, Ryan CW, Beer TM. Resistance exercise reduces body fat and insulin during androgen-deprivation therapy for prostate cancer. Oncol Nurs Forum. 2015;42:348-56.

48. Nilsen TS, Raastad T, Skovlund E, Courneya KS, Langberg CW, Lilleby W, et al. Effects of strength training on body composition, physical functioning, and quality of life in prostate cancer patients during androgen deprivation therapy. Acta Oncol. 2015;54:1805-13.

49. Winters-Stone KM, Lyons KS, Dobek J, Dieckmann NF, Bennett JA, Nail L, et al. Benefits of partnered strength training for prostate cancer survivors and spouses: results from a randomized controlled trial of the Exercising Together project. J Cancer Surviv. 2016;10:633-44.

50. Hojan K, Kwiatkowska-Borowczyk E, Leporowska E, Milecki P. Inflammation, cardiometabolic markers, and functional changes in men with prostate cancer. A randomized controlled trial of a 12-month exercise program. Pol Arch Intern Med. 2017; $127: 25-35$.

51. Galvão DA, Taaffe DR, Spry N, Cormie P, Joseph D, Chambers SK, et al. Exercise preserves physical function in prostate cancer patients with bone metastases. Med Sci Sports Exerc. 2018;50:393-9.

52. Dawson JK, Dorff TB, Todd Schroeder E, Lane CJ, Gross ME, Dieli-Conwright CM. Impact of resistance training on body composition and metabolic syndrome variables during androgen deprivation therapy for prostate cancer: a pilot randomized controlled trial. BMC Cancer. 2018;18:368.

53. Alibhai SMH, Santa Mina D, Ritvo P, Tomlinson G, Sabiston C, Krahn M, et al. A phase II randomized controlled trial of three exercise delivery methods in men with prostate cancer on androgen deprivation therapy. BMC Cancer. 2019;19:2.

54. Ndjavera W, Orange ST, O'Doherty AF, Leicht AS, Rochester M, Mills R, et al. Exercise-induced attenuation of treatment sideeffects in patients with newly diagnosed prostate cancer beginning androgen-deprivation therapy: a randomised controlled trial. BJU Int. 2020;125:28-37.

55. Buffart LM, Sweegers MG, May AM, Chinapaw MJ, van Vulpen JK, Newton RU, et al. Targeting exercise interventions to patients with cancer in need: an individual patient data meta-analysis. $\mathbf{J}$ Natl Cancer Inst. 2018;110:1190-1200.

56. Van Vulpen JK, Sweegers MG, Peeters PHM, Courneya KS, Newton RU, Aaronson NK, et al. Moderators of exercise effects on cancer-related fatigue: a meta-analysis of individual patient data. Med Sci Sports Exerc. 2020;52:303-14.

57. Hart PD, Buck DJ. The effect of resistance training on healthrelated quality of life in older adults: systematic review and metaanalysis. Health Promot Perspect. 2019;9:1-12.

58. Cramp F, James A, Lambert J. The effects of resistance training on quality of life in cancer: a systematic literature review and meta-analysis. Support Care Cancer. 2010;18:1367-76.

59. Sweegers MG, Altenburg TM, Chinapaw MJ, Kalter J, Verdonckde Leeuw IM, Courneya KS, et al. Which exercise prescriptions 
improve quality of life and physical function in patients with cancer during and following treatment? A systematic review and meta-analysis of randomised controlled trials. Br J Sports Med. 2018;52:505-13.

60. Brown JC, Huedo-Medina TB, Pescatello LS, Ryan SM, Pescatello SM, Moker E, et al. The efficacy of exercise in reducing depressive symptoms among cancer survivors: a meta-analysis. PLoS ONE. 2012;7:e30955.

61. Gordon BR, McDowell CP, Hallgren M, Meyer JD, Lyons M, Herring MP. Association of efficacy of resistance exercise training with depressive symptoms: meta-analysis and meta-regression analysis of randomized clinical trials. JAMA Psychiatry. 2018;75:566-76.

62. Gordon BR, McDowell CP, Lyons M, Herring MP. The effects of resistance exercise training on anxiety: a meta-analysis and metaregression analysis of randomized controlled trials. Sports Med. 2017;47:2521-32.

63. Lahart IM, Metsios GS, Nevill AM, Carmichael AR. Physical activity for women with breast cancer after adjuvant therapy. Cochrane Database Syst Rev. 2018;1:CD011292.

64. Mishra SI, Scherer RW, Snyder C, Geigle PM, Berlanstein DR, Topaloglu O. Exercise interventions on health-related quality of life for people with cancer during active treatment. Cochrane Database Syst Rev. 2012;2012:CD008465.

65. Pompe RS, Krüger A, Preisser F, Karakiewicz PI, Michl U, Graefen M, et al. The impact of anxiety and depression on surgical and functional outcomes in patients who underwent radical prostatectomy. Eur Urol Focus. 2018: S2405-4569(18)30410-3.

66. Hayes SC, Newton RU, Spence RR, Galvão DA. The Exercise and Sports Science Australia position statement: exercise medicine in cancer management. $J$ Sci Med Sport. 2019;22:1175-99.

67. Cella D, Eton DT, Lai JS, Peterman AH, Merkel DE. Combining anchor and distribution-based methods to derive minimal clinically important differences on the Functional Assessment of Cancer Therapy (FACT) anemia and fatigue scales. J Pain Symptom Manag. 2002;24:547-61.

68. Van Belle S, Paridaens R, Evers G, Kerger J, Bron D, Foubert J, et al. Comparison of proposed diagnostic criteria with FACT-F and VAS for cancer-related fatigue: proposal for use as a screening tool. Support Care Cancer. 2005;13:246-54.

69. Cella D, Lai JS, Chang CH, Peterman A, Slavin M. Fatigue in cancer patients compared with fatigue in the general United States population. Cancer. 2002;94:528-38.

70. Schwartz AL, Meek PM, Nail LM, Fargo J, Lundquist M, Donofrio $\mathrm{M}$, et al. Measurement of fatigue. determining minimally important clinical differences. J Clin Epidemiol. 2002;55:239-44.

71. Nordin Å, Taft C, Lundgren-Nilsson Å, Dencker A. Minimal important differences for fatigue patient reported outcome measures-a systematic review. BMC Med Res Methodol. 2016;16:62.

72. Pearman T, Yanez B, Peipert J, Wortman K, Beaumont J, Cella D. Ambulatory cancer and US general population reference values and cutoff scores for the functional assessment of cancer therapy. Cancer. 2014;120:2902-9.

73. Skaltsa K, Longworth L, Ivanescu C, Phung D, Holmstrom S. Mapping the FACT-P to the preference-based EQ-5D questionnaire in metastatic castration-resistant prostate cancer. Value Health. 2014;17:238-44.

74. Osoba D, Rodrigues G, Myles J, Zee B, Pater J. Interpreting the significance of changes in health-related quality of life scores. $\mathrm{J}$ Clin Oncol. 1998;16:139-44.

75. Cocks K, King MT, Velikova G, de Castro G Jr, Martyn StJames M, Fayers PM, et al. Evidence-based guidelines for interpreting change scores for the European Organisation for the Research and Treatment of Cancer Quality of Life Questionnaire Core 30. Eur J Cancer. 2012;48:1713-21.

76. Snyder CF, Blackford AL, Okuyama T, Akechi T, Yamashita H, Toyama T, et al. Using the EORTC-QLQ-C30 in clinical practice for patient management: identifying scores requiring a clinician's attention. Qual Life Res. 2013;22:2685-91.

77. Wyrwich KW, Tierney WM, Babu AN, Kroenke K, Wolinsky FD. A comparison of clinically important differences in healthrelated quality of life for patients with chronic lung disease, asthma, or heart disease. Health Serv Res. 2005;40:577-91. 